\title{
Analisis Data Magnetisasi Remanen Isotermal dengan Software IRMUNMIX
}

\author{
Dedi Setiabudidaya* \\ Jurusan Fisika, Universitas Sriwijaya \\ Jl. Raya Prabumulih KM 32 Sumatera Selatan
}

\section{Intisari}

Telah dilakukan kajian kinerja software IRMUNMIX terhadap sampel yang terindikasi hanya memiliki satu komponen mineral magnetik. Hasil menunjukkan bahwa software IRMUNMIX mampu mendeteksi komponen mineral magnetik dengan kontribusi yang sangat minimal.

KATA KUNCI: magnetisasi, kurva akuisisi, saturasi

\section{PENDAHULUAN}

Tehnik magnetisasi remanen isotermal (MRI) banyak digunakan di dalam kajian magnetism batuan, paleomagnetism, dan magnetism lingkungan. Kurva yang dihasilkan dengan menggunakan tehnik ini adalah relatif sangat sederhana yaitu berbentuk sigmoid dengan nilai saturasinya menentukan mineral magnetik yang dikandung dalam sampel (sebagai contoh lihat Gambar 1). Sinyal magnetik pada kurva MRI ini sering kali didominasi oleh magnetit, sehingga keberadaan mineral magnetik lainnya umumnya tidak begitu tampak.

Robertson dan France (1994) dalam Kruiver dkk (2001) [1] mengamati secara eksperimental bahwa kurva akuisisi MRI tersebut sesuai dengan kurva log-gaussian kumulatif (LGK), sehingga suatu kurva akuisisi dapat diuraikan ke dalam sejumlah kurva LGK yang masing-masing dicirikan oleh nilai saturasi (SIRM), koersitivitas (B1/2) dan dispersinya (DP), lihat Gambar 2. Program pengolah data MRI telah tersedia di

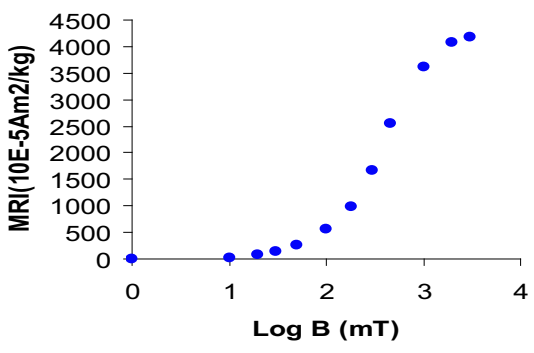

Gambar 1: Contoh kurva akuisisi suatu sampel dengan menggunakan tehnik MRI. Bila nilai saturasi yang terjadi di sekitar nilai $\mathrm{B}=300$ $\mathrm{mT}$ mengindikasikan keberadaan mineral magnetit.

\footnotetext{
*E-MAIL: setiabudidaya@hotmail.com
}

(c) Jurusan Fisika FMIPA ITS

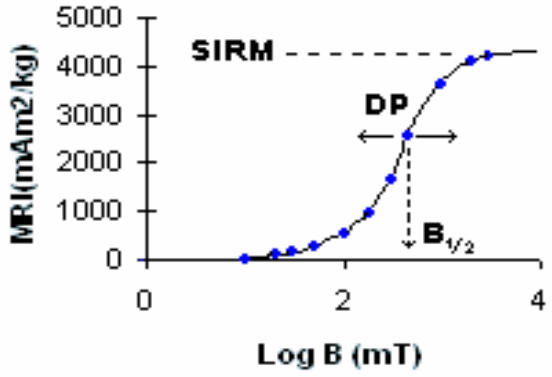

Gambar 2: Parameter penentu kurva LGK.

internet dan dapat di-download secara bebas adalah program IRM-CLG [1] dan program IRMUNMIX [2, 3].

\section{TINJAUAN PUSTAKA}

\section{A. Hasil Sebelumnya}

Setiabudidaya [4] mengadopsi ide program IRM-CLG yang berbasis Excel [1] dan memanfaatkannya untuk menganalisis sejumlah data MRI. Data sampel diolah menjadi kurva LAP (Linear Acquisition Plot) dan kurva GAP (Gradient Acquisition Plot) (lihat Gambar 3). Jumlah komponen fase magnetik yang terkandung dalam sampel dapat dilihat dengan cukup jelas pada kurva GAP yaitu akan berbentuk bimodal yang dapat diinterpretasikan sebagai dua komponen. Pencocokan model dengan data hasil pengukuran hanya dilakukan pada kurva LAP.

Di dalam kajian tersebut dua kelompok sampel batupasir merah masing-masing berjumlah 27 (dua puluh tujuh) buah diberikan medan magnet secara bertahap hingga $3000 \mathrm{mT}$ $[5,6]$. Kelompok pertama adalah sampel yang telah digunakan dalam pengukuran paleomagnetik dan telah men- 
Linier Akuisisi Plot (LAP)

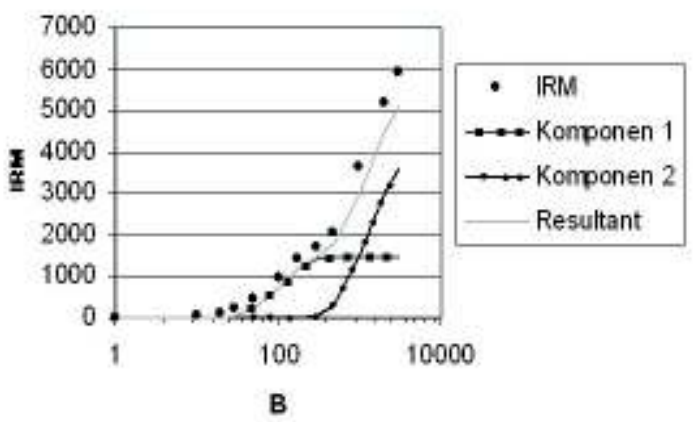

(a)

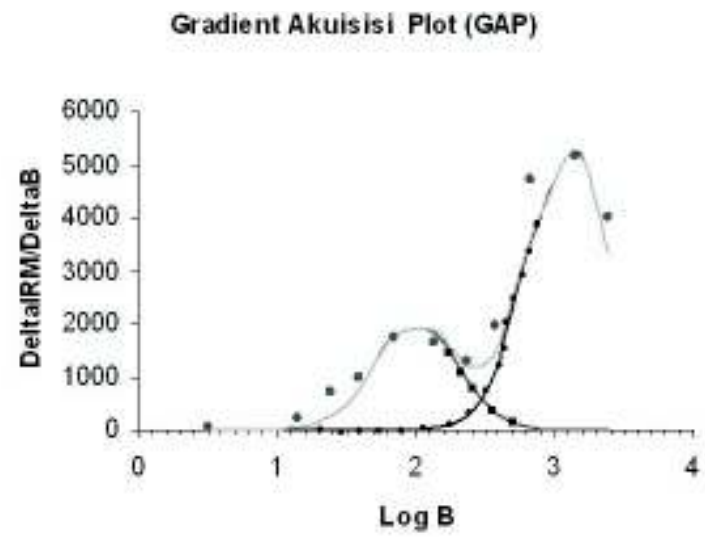

(b)

Gambar 3: Hasil tampilan kurva LAP dan GAP (Setiabudidaya, 2004)

jalani demagnetisasi termal hingga $700^{\circ} \mathrm{C}-720^{\circ} \mathrm{C}$. Sedangkan kelompok yang lain adalah sampel yang tidak mendapatkan perlakuan termal (kontrol). Empat dari 27 sampel, yaitu sampel DV24, DV45, DV46 dan DV47 menunjukkan satu komponen mineral magnetik. Sedangkan sampel DV27, DV35, DV36, DV39, DV41, DV42, DV43, dan DV43 menunjukkan satu komponen mineral magnetik pada kelompok kontrol namun dua komponen mineral magnetik pada kelompok perlakuan. Sampel lainnya menunjukkan dua komponen mineral magnetik baik pada kelompok perlakuan maupun pada kelompok kontrol.

Pada kelompok kontrol diperoleh hasil rata-rata $(\mathrm{N}=15)$ untuk komponen pertama $\log \mathrm{B}_{1 / 2}=1,792$ dan $\mathrm{DP}=0,447$ serta komponen kedua $\log \mathrm{B}_{1 / 2}=2,728$ dan $\mathrm{DP}=0,341$. Pada kelompok perlakuan diperoleh hasil rata-rata $(\mathrm{N}=23)$ untuk komponen pertama $\log \mathrm{B}_{1 / 2}=1,786$ dan $\mathrm{DP}=0,376$ serta komponen kedua $\log \mathrm{B}_{1 / 2}=3,079$ dan $\mathrm{DP}=0,365$. Uji statistik menunjukkan bahwa perlakuan tidak menyebabkan terjadinya perbedaan koersitivitas pda komponen pertama. Perbedaan terjadi pada komponen kedua di mana terjadi peningkatan koersitivitas yang dapat diinterpretasikan sebagai indikasi terjadinya oksidasi pada sampel yang mengakibatkan terjadinya mineral hematit. Pada sebagian sampel terjadi peningkatan intensitas SIRM yang sangat drastis. Hal ini dapat dijelaskan sebagai akibat dari perlakuan termal yang mengakibatkan penguraian senyawa-senyawa lempung menjadi magnetit. Pada tulisan ini akan dibahas penggunaan software IRMUNMIX untuk menganalis data MRI sampel DV24, DV45, DV46, dan DV47 yang menunjukkan satu komponen mineral baik pada kelompok perlakuan (berakhiran $-\mathrm{H}$ ) maupun pada kelompok kontrol (berakhiran -UH) (lihat Tabel 1).

\section{B. Deskripsi Software IRMUNIX}

Software IRMUNMIX ditulis oleh Dave Heslop (heslop@geo.uu.nl) dalam bahasa Fortran90. Data input terdiri dari intensitas medan magnet yang diberikan dan intensitas MRI yang terukur dan cara penulisan keduanya pada file data adalah dengan cara dipisahkan menggunakan karakter tab. Agar software bekerja dengan baik, kedua besaran tersebut harus mempunyai nilai yang monoton naik. Jika tidak demikian, program akan terhenti atau jika tidak naik secara konsisten, user akan diminta persetujuannya di mana software akan memanfaatkan gradient absolut untuk mencari data pengganti sehingga software akan bekerja bukan dengan data mentah user.

Algoritma pencocokan yang digunakan menghendaki data logaritma intensitas medan magnet harus memiliki interval yang sama dan jika tidak akan muncul pesan untuk menggunakan 'smoothing spline'. Di sini ada dua pilihan yang diberikan kepada user yaitu koefisien smoothing dan deviasi terhadap nilai awal. Koefisien smoothing yang harus dipilih user adalah antara 1 yang berarti smoothing maksimum dan 0 yang berarti tidak dilakukan smoothing terhadap data awal. Sedangkan deviasi terhadap data awal diberikan dalam bentuk persentase, misal user memilih 0.05 (= 5\%) yang bearti maksimum deviasi yang diperbolehkan antara set data hasil smoothing dengan data asal adalah 5\%. Kadang kala penggunaan 'smoothing spline' akan menghasilkan data yang 'spurious' oleh karena itu kepada user diberikan pilihan untuk melihat kurva gradiennya. Dan jika terjadi yang demikian, maka prosedur berikutnya adalah melakukan 'cropping' yaitu data yang 'spurious' tadi perlu dihapus dan tidak diikutsertakan pada proses berikutnya.

Selanjutnya user akan diminta memasukkan parameter analisis yang akan digunakan yaitu apakah sampel mencapai nilai saturasinya dan apakah user menghendaki program secara otomatis menentukan jumlah komponen mineral magnetik yang dikandung sampel. Jika user menginginkan jumlah komponen tertentu pada model MRI yang diinginkan, software akan meminta 3 (tiga) parameter untuk masing-masing komponen yang harus diberikan oleh user, yaitu

1. Kontribusi relative komponen terhadap kurva MRI secara keseluruhan (kontr.)

2. Koersitivitas rata-rata $\left(B_{1 / 2}\right.$ dalam log)

3. Parameter disperse (DP) 
TABEL I: Hasil analisis sampel kontrol dan sampel setelah demagnetisasi termal yang hanya memiliki satu komponen fase magnetik (kontr. $=$ kontribusi ). $\mathrm{B}_{1 / 2}$ dan DP dalam $\log (\mathrm{mT})$, SIRM dalam $10 \mathrm{E}-5 \mathrm{~A} \mathrm{~m}^{2} / \mathrm{kg}$ dan kontr. dalam $\%$.

\begin{tabular}{|c|c|c|c|c|c|c|c|c|}
\hline \multirow[t]{2}{*}{ Sampel } & \multicolumn{4}{|c|}{ Komponen 1} & \multicolumn{4}{|c|}{ Komponen 2} \\
\hline & $\mathrm{B}_{1 / 2}$ & DP & SIRM & Kontr. & $\mathrm{B}_{1 / 2}$ & DP & SIRM & Kontr. \\
\hline DV24-UH & - & - & - & - & 2,856 & 0,396 & 106,733 & 100 \\
\hline DV45-UH & - & - & - & - & 2,800 & 0,396 & 176,418 & 100 \\
\hline DV46-UH & - & - & - & - & 2,700 & 0,318 & 90,000 & 100 \\
\hline DV47-UH & - & - & - & - & 2,727 & 0,354 & 91,809 & 100 \\
\hline DV24-U & - & - & - & - & 1,900 & 0,326 & 1237,500 & 100 \\
\hline DV45-U & - & - & - & - & 1,844 & 0,312 & 3499,650 & 100 \\
\hline DV46-U & - & - & - & - & 1,900 & 0,328 & 927,271 & 100 \\
\hline DV47-U & - & - & - & - & 1,900 & 0,336 & 3136,320 & 100 \\
\hline
\end{tabular}

Setelah prosedur akhir selesai dieksekusi, software akan menginformasikan kepada user parameter untuk masingmasing komponen mineral juga nilai lainnya yang berkaitan dengan proses pencocokan yaitu nilai konvergensi (XLOGL, dalam $\log$ ), kesalahan prosedur (IFAULT $=0)$, jika berhasil akan ditampilkan IFAULT $=0$ ) dan jumlah iterasi yang diperlukan oleh model untuk mencapai konvergensi. File output untuk grafik hasil pencocokan telah dihilangkan di dalam versi ini sehingga user diminta menggunakan program aplikasi lainnya seperti Excel (fungsi NORMDIST), Matlab (fungsi NORMPDF dan NORMCDF), dan Mathematica (fungsi PDF dan CDF).

\section{HASIL DAN PEMBAHASAN}

\section{A. Hasil dari Software IRMUNMIX}

Tabel 2 adalah hasil dari penggunaan software IRMUNMIX pada sampel DV24, DV45, DV46, dan DV47 untuk kelompok kontrol (-UH) dan kelompok perlakuan $(-\mathrm{H})$. Meskipun secara numerik ke delapan sampel menunjukkan dua komponen mineral magnetik, telaah lebih lanjut perlu dilakukan khususnya terhadap sampel DV24-H, DV46-H, dan DV47-H. Parameter magnetik yang diperoleh memiliki nilai B1/2 berdekatan antara komponen satu dan komponen dua serta nilai DP yang relatif cukup besar. Indikasi pengaruh mineral magnetit yang memiliki intensitas yang relatif besar sehingga mengaburkan keberadaan komponen mineral magnetik lainnya cukup jelas. Selain dari pada itu, untuk kasus yang demikian penggunaan software IRMUNMIX perlu dilakukan berulang-ulang dengan mempertimbangkan berbagai hal dan tidak diserahkan sepenuhnya pada besaran statistik yang ditampilkan oleh program tetapi juga pada common sense dari user.

Gambar 4 adalah hasil model data MRI DV24-UH dengan menggunakan software IRMUNMIX dan ditampilkan dengan memanfaatkan program aplikasi Excel. Terlihat pada kurva GAP, sampel mengandung dua komponen mineral magnetik.

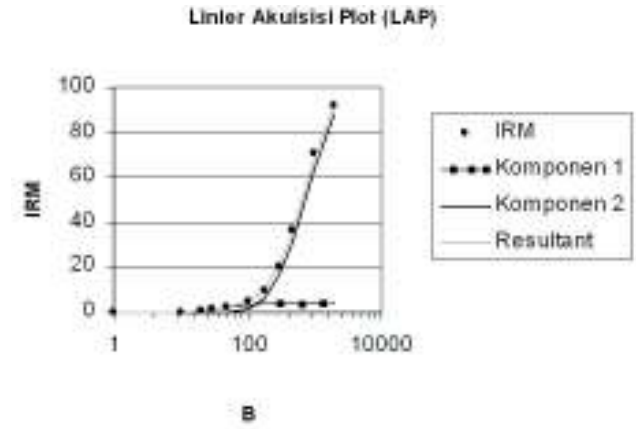

(a)

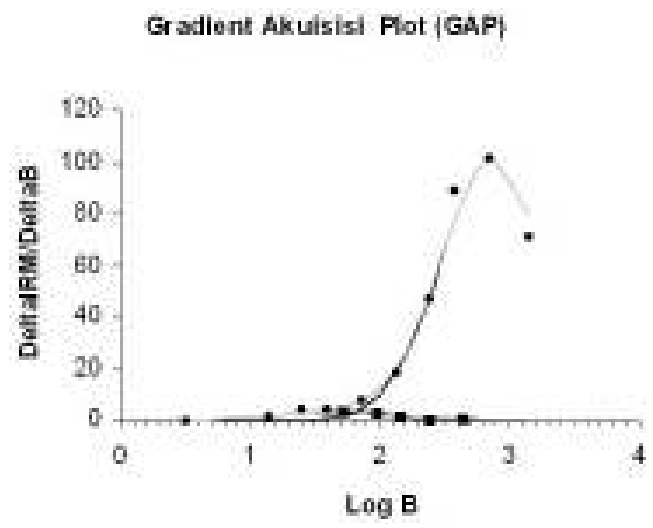

(b)

Gambar 4: Hasil model data DV24-UH dari software IRMUNMIX dan tampilan grafik dengan menggunakan Excel

\section{SIMPULAN}

Penggunaan software IRMUNMIX dalam menganalisis data MRI sangat membantu peneliti dalam menguraikan komponen magnetik yang dikandung oleh suatu sampel secara cepat dan user friendly. Di dalam kajian ini ditunjukkan bahwa software IRMUNMIX berhasil mendeteksi komponen mineral magnetik yang tidak terdeteksi oleh software lainnya. Jumlah titik data yang akan diolah dan dicocokan akan mempengaruhi keberhasilan penggunaan software ini. Hal 
TABEL II: Hasil analisis sampel kelompok kontrol dan sampel kelompok perlakuan dengan menggunakan software IRMUNMIX

\begin{tabular}{|c|c|c|c|c|c|c|c|c|}
\hline \multirow[t]{2}{*}{ Sampel } & \multicolumn{4}{|c|}{ Komponen 1} & \multicolumn{4}{|c|}{ Komponen 2} \\
\hline & $B_{1 / 2}$ & DP & SIRM & Kontr. & $B_{1 / 2}$ & DP & SIRM & Kontr. \\
\hline DV24-UH & 1,655 & 0,450 & 4,29 & 0,04 & 2,876 & 0,407 & 102,96 & 0,96 \\
\hline DV45-UH & 1,764 & 0,750 & 3,47 & 0,02 & 2,784 & 0,340 & 169,92 & 0,98 \\
\hline DV46-UH & 1,855 & 0,667 & 1,89 & 0,02 & 2,744 & 0,346 & 92,71 & 0,98 \\
\hline DV47-UH & 1,815 & 0,713 & 2,81 & 0,03 & 2,750 & 0,335 & 90,75 & 0,97 \\
\hline DV24-U & 1,811 & 0,658 & 381,60 & 0,30 & 1,911 & 0,278 & 890,39 & 0,70 \\
\hline DV45-U & 2,616 & 0,297 & 58,38 & 0,29 & 3,044 & 0,500 & 142,94 & 0,71 \\
\hline DV46-U & 1,864 & 0,212 & 563,95 & 0,56 & 2,198 & 0,745 & 443,10 & 0,44 \\
\hline DV47-U & 1,963 & 0,710 & 718,02 & 0,23 & 1,981 & 0,3136 & 2403,82 & 0,77 \\
\hline
\end{tabular}

ini dikarenakan pengolahan data dilakukan dengan memanfaatkan analisis statistik baik Tabel F maupun Tabel t. Se- makin besar jumlah data yang diolah semakin baik kinerja dari software IRMUNMIX.
[1] P.P.Kruiver,M.J. Dekker, D. Heslop, Earth Planet Sci. Lett.,vol.189, 269-276,(2001)

[2] D.Heslop,M.J.Dekker, P.P. Kruiver, I.H.M. Oorschot. Geophys. J. Int. 148, 58-64.(2002)

[3] D. Setiabudidaya, Kajian Magnetisasi Remanen Isotermal terhadap Sampel Paleomagnetik setelah Didemagnetisasi secara Termal, Seminar MIPA IV. Kampus ITB. 6-7 Oktober 2004.
[4] http://www.geo.uu.nl/ forth/Software/soft.html

[5] D. Setiabudidaya, Magnetostratigraphy and Tectonic Rotation in South Wales, $P h D$ thesis. University of Liverpool,(1991).

[6] D. Setiabudidaya, J.D.A.Piper, J. Shaw.Tectonophysics, 231,257280(1994) 